\title{
Thermal-Type Blood Flow Sensor on Titanium Microneedle
}

\author{
Takashi Mineta, Yuki Tanahashi, Eiji Makino, Satoshi Toh ${ }^{1}$, \\ Takahiro Kawashima ${ }^{2}$ and Takayuki Shibata ${ }^{2}$ \\ Graduate School of Science and Technology, Hirosaki University, \\ 3 Bunkyo-cho, Hirosaki, Aomori 036-8561 Japan \\ ${ }^{1}$ Graduate School of Medicine, Hirosaki University, \\ 5 Zaifu-cho, Hirosaki, Aomori 036-8562, Japan \\ ${ }^{2}$ Department of Production Systems Engineering, Toyohashi University of Technology, \\ 1-1 Hibarigaoka, Tempaku-cho, Toyohashi 441-8580, Japan
}

(Received August 1, 2008; accepted November 18, 2008)

Key words: thermal flow sensor, Ti needle, blood flow, electrochemical etching

In this paper, we describe a thermal-type blood flow microsensor that is inserted in a blood vessel and used to detect the flow rate change caused by a thrombus. The sensor is based on a Ti microneedle, on which a Pt microheater and a Pt-Au microthermocouple are formed. The microneedle was fabricated from a Ti sheet of $50 \mu \mathrm{m}$ thickness by electrochemical etching and chemical etching in succession. The characteristics of the fabricated sensor were evaluated in flows of water and a viscous fluid in an artificial flow channel $1.2 \mathrm{~mm}$ in diameter. At a safe heating level $\left(\leq 42^{\circ} \mathrm{C}\right)$, the sensor could measure a flow velocity of up to several $\mathrm{cm} / \mathrm{s}$. The sensor has high sensitivity in the flow velocity range of $0-1 \mathrm{~cm} / \mathrm{s}$, indicating that it can detect the blood flow reduction due to a thrombus in a vein.

\section{Introduction}

Advances in microsurgery have improved the results of free tissue transfer operations and organ graft operations such as liver transplantation. However, thrombi tend to form near anastomotic sites in blood vessels. Tissue failure occurs in $5-10 \%$ of free tissue transfer operations, mainly owing to thrombosis within the first $24 \mathrm{~h}$ after surgery. Thus, there is a need for adequate and reliable monitoring techniques. ${ }^{(1)}$

To monitor the microvascular blood flow, an implantable ultrasonic Doppler probe ${ }^{(2)}$ and electromagnetic flow measurement method ${ }^{(3)}$ have been developed. However, the implantable devices require additional surgery for removal from the body.

We have focused on the detection of blood flow in a small blood vessel with a diameter of about $1 \mathrm{~mm}$, typical of blood vessels in fingers. In our previous work, we developed a mechanical pulsation sensor with a shape memory alloy film actuator that clips a blood vessel and detects the pulsation decrease caused by a thrombus. ${ }^{(4,5)}$ ${ }^{*}$ Corresponding author: e-mail: mineta@cc.hirosaki-u.ac.jp 
Although the sensor was sufficiently sensitive to detect blood flow obstruction in an artery, it was not easy to use for blood flow detection in a vein owing to the weak pulsation. The typical blood flow rate in a $1 \mathrm{~mm}$ vein is estimated to be several $\mathrm{ml} / \mathrm{min} .{ }^{(6)}$ A highly sensitive flow sensor is necessary to detect a decrease in blood flow in a vein.

The anemometric method is suitable for the sensitive measurement of fluid flow. ${ }^{(7)}$ A wire-shaped anemometer has been used to measure the blood flow in the ascending aorta. ${ }^{(8)}$

In this paper, we describe the fabrication of a thermal-type blood flow microsensor for the purpose of thrombus detection in a small-diameter vein. The sensor, based on a Ti microneedle with a microheater and a microthermocouple, is inserted in a blood vessel to detect the flow rate change caused by a thrombus. The detection characteristics of the fabricated sensor are also described, focusing particularly on its sensitivity in the slowflow-rate range.

\section{Structure and Principle}

The schematic of the blood flow sensor is shown in Fig. 1. The sensor is inserted into a fine blood vessel with an inner diameter of about $1 \mathrm{~mm}$. Figure 2 shows the structure and design of the sensor. The inserting needle is made of Ti, which has features of high biocompatibility and corrosion resistance. The needle is $1.2 \mathrm{~mm}$ long, $50 \mu \mathrm{m}$ thick, and $300 \mu \mathrm{m}$ wide. A microheater pattern of Pt film (100 nm thick, $30 \mu \mathrm{m}$ wide) is formed on a polyimide layer on the Ti needle. A Pt (100 nm)-Au (200 nm) micro-thermocouple is laminated on the heater layer on top of a polyimide interlayer. The Pt-Au junction of the microthermocouple is located at the center of the meandering pattern of the $\mathrm{Pt}$ microheater.

The needle-shaped sensor is heated using the microheater with a constant electric current, and the temperature of the sensor decreases with increasing blood flow rate in the vessel. This change in sensor temperature is measured with the laminated Pt-Au thermocouple.

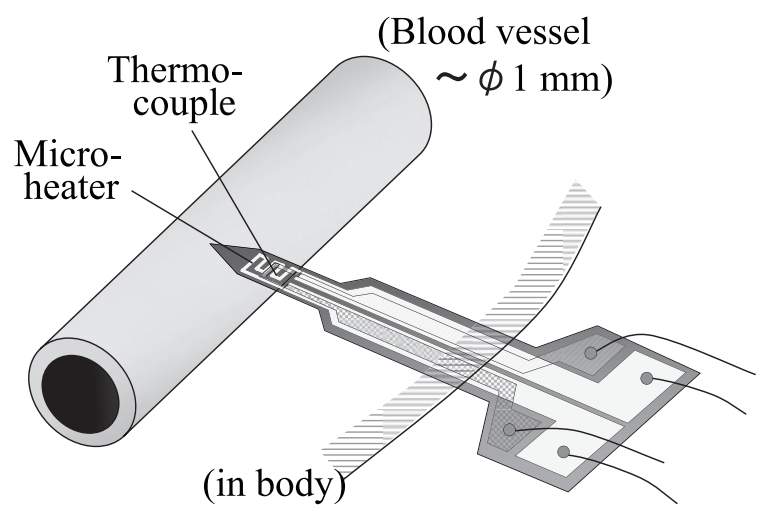

Fig. 1. Schematic of the blood flow microsensor. 


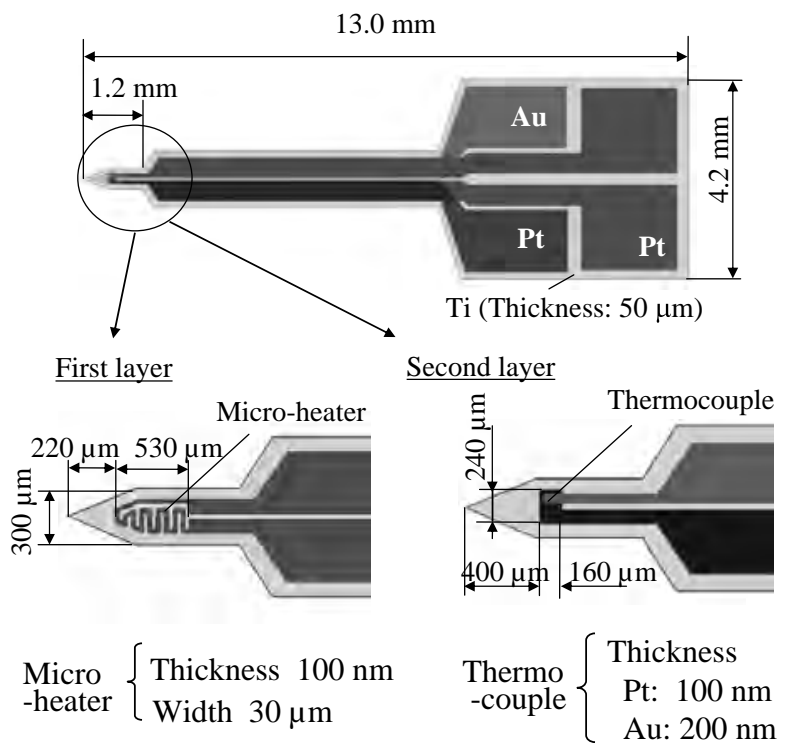

Fig. 2. Structure and design of the blood flow microsensor.

\section{Electrochemical Etching of Titanium Sheet}

The etching processes available for Ti sheet were examined prior to the fabrication of the sensor. Conventional chemical etching in a hydrofluoric (HF) solution was not suitable for the precision patterning of Ti sheet owing to the wide side etching. Our preliminary experiment showed that the etch factor (etched depth/side etching) of chemical etching of $\mathrm{Ti}$ in a HF solution was less than 0.5. Electrochemical etching is suitable for the patterning of a Ti substrate. ${ }^{(9)}$ We have also studied the electrochemical etching of Ti-Ni shape memory alloy with a high etch factor in LiCl-ethanol and LiClmethanol electrolyte solutions. ${ }^{(10)}$ It has also been found that Ti was dissolved similarly to Ti-Ni alloy in the electrochemical etching process.

To apply this electrochemical etching process to the patterning of $\mathrm{Ti}$, basic etching characteristics were studied in detail. A Ti $(99.5 \%)$ sheet $\left(20 \times 20 \mathrm{~mm}^{2}\right)$ of $200 \mu \mathrm{m}$ thickness was used. A negative photoresist (Tokyo Ohka, Ltd., OMR-83) pattern was formed on the Ti sheet as an etching mask (line and space: 30 and $30 \mu \mathrm{m}$ ). Constant dc voltage was applied between the Ti substrate anode and the counter cathode of stainless steel plate $\left(50 \times 50 \mathrm{~mm}^{2}\right)$ in an electrolyte solution of $\mathrm{LiCl}$-methanol $\left(1 \mathrm{~mol} / \mathrm{L}, 25^{\circ} \mathrm{C}\right)$.

With an applied voltage of $10 \mathrm{~V}$, the Ti sheet was etched successfully with an etch rate of about $15 \mu \mathrm{m} / \mathrm{min}$ and an etch factor of about 1.5. As shown in Fig. 3(a), uniform etching with a smooth etched surface occurred when the Ti sheet was not etched clearly through. However, electrochemical etching tended to proceed non-uniformly, as shown 


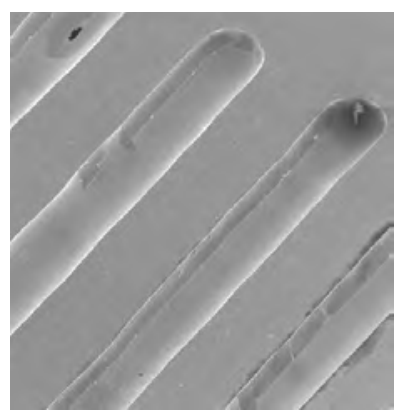

(a)

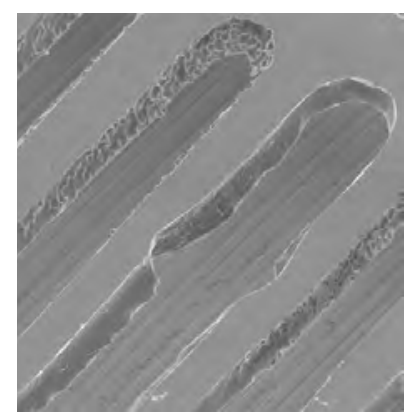

(b)

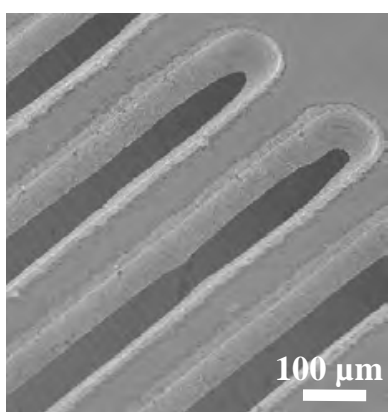

(c)

Fig. 3. Etching of Ti sheet. (a) Electrochemical etching (half-etching), (b) electrochemical etching (sheet-through etching), (c) electrochemical etching ( $40 \mu \mathrm{m}$, half-etching) and additional chemical etching $(10 \mu \mathrm{m}$, sheet-through).

in Fig. 3(b), because the electrolytic current distribution became non-uniform. ${ }^{(10)}$ To overcome this problem, the electrochemical etching was stopped before the Ti sheet was pierced, then chemical etching in HF solution was used to pierce the sheet (Fig. 3(b)). The two-step etching produced uniform through-the-sheet etching with only small side etching, as shown in Fig. 3(c).

\section{Fabrication of Blood Flow Sensor}

The sequence of the fabrication of the blood flow sensor is shown in Fig. 4, as follows. (a) A cold-rolled Ti sheet of $50 \mu \mathrm{m}$ thickness was used. An insulator layer of photosensitive polyimide (Toray, UR-3100E) was formed by spin coating and baking $(2 \mu \mathrm{m})$. (b) A Pt circuit pattern $(100 \mathrm{~nm})$ for the microheater was formed by sputter deposition and liftoff technique. (c) A second polyimide layer was formed as interlayer insulation. (d) A microthermocouple of Pt (100 nm) and Au (200 nm) was formed by sputter deposition and lift-off technique. (e) A third polyimide layer was formed for final passivation. (f) After a negative photoresist (OMR-83) pattern was formed, the Ti substrate was halfetched to about $40 \mu \mathrm{m}$ depth by electrochemical etching in a LiCl-methanol solution. (g) The Ti sheet was etched through in an HF solution. (h) The needle-shaped sensor was separated from the Ti sheet after the photoresist was removed.

Figure 5 shows the completed sensor. After the fabrication process, $\mathrm{Pt}, \mathrm{Au}$, and $\mathrm{Cu}$ lead wires $(\varphi 0.1 \mathrm{~mm})$ were attached to the bonding pad of the thermocouple $(\mathrm{Pt})$, the thermocouple $(\mathrm{Au})$, and the heater, respectively, with a conductive resin.

\section{Sensing Characteristics}

The microthermocouple was calibrated in a temperature-controlled oven. Figure 6 shows the relationship between the measured thermal-electromotive force and the 
(a) Polyimide patterning

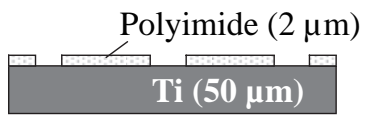

(b) Formation of Pt microheater

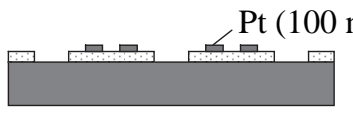

(c) Polyimide insulation

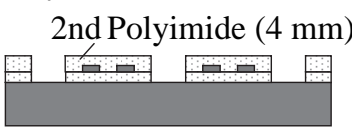

(d) Formation of Pt-Au thermocouple

Pt (100 nm) Au (200 nm)

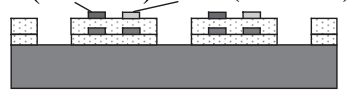

(e) Polyimide insulation

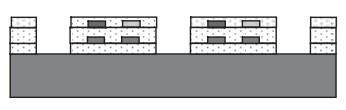

(f) Electrochemical etching $(40 \mu \mathrm{m})$

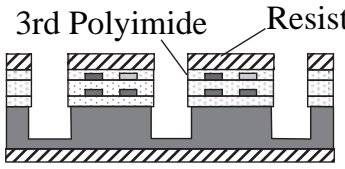

(g) Sheet-through etching in HF solution $(10 \mu \mathrm{m})$

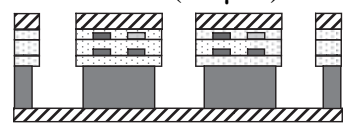

(h) Sensor separation (photoresist removal)

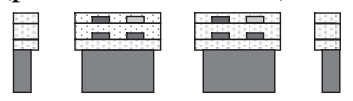

Fig. 4. Fabrication flow of the blood flow sensor.

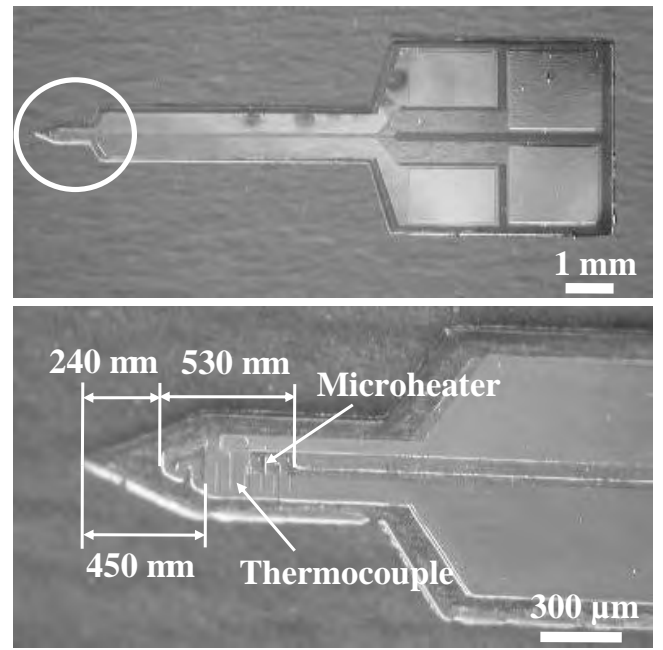

Fig. 5. Completed blood flow sensor.

atmospheric temperature in the oven. The fabricated Pt-Au microthermocouple had a sensitivity of about $7.1 \mu \mathrm{V} /{ }^{\circ} \mathrm{C}$ in the temperature range of 25 to $50^{\circ} \mathrm{C}$, which showed good agreement with the reported value of $7.2 \mu \mathrm{V} /{ }^{\circ} \mathrm{C} .{ }^{(11)}$ 


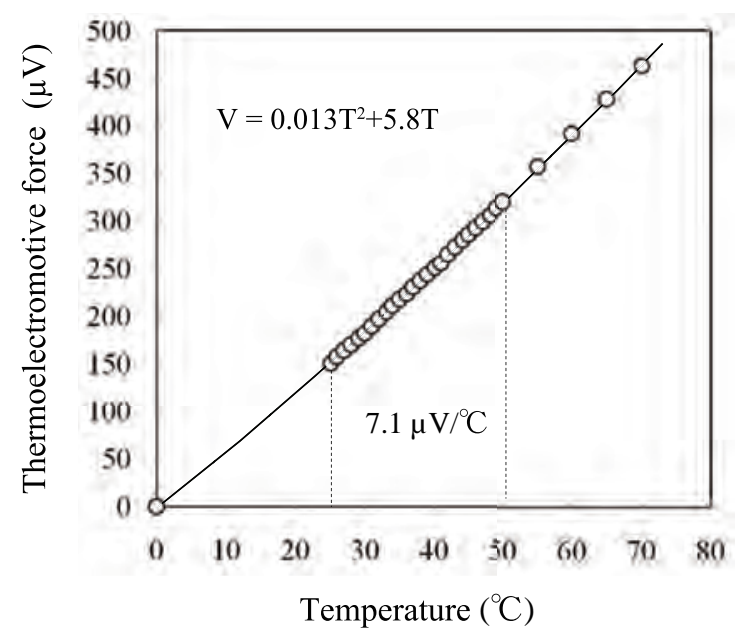

Fig. 6. Calibration curve of the Pt-Au microthermocouple.

The sensing properties of the blood flow sensor were evaluated in a flow channel of acrylic resin (inner diameter: $1.2 \mathrm{~mm}$ ). The experimental setup is shown in Fig. 7. The sensor was inserted in the flow channel. The flow rate of the fluid was varied by changing the height of the supply vessel.

Figure 8 shows the change in the sensor temperature, obtained from the calibration curve in Fig. 6, during heating in standing water $\left(36^{\circ} \mathrm{C}\right)$. The sensor temperature increased rapidly after the heating current was turned on, but it was saturated within several seconds. When the heating current of the microheater was $11 \mathrm{~mA}$ or lower, the maximum temperature of the sensor was controlled below $42^{\circ} \mathrm{C}$, which is the permitted upper limit temperature in vivo. Under this heating condition, the output voltage of the sensor was measured as the flow rate of the water $\left(36^{\circ} \mathrm{C}\right)$ in the channel was varied.

Figure 9 shows the sensor temperature as a function of water flow rate. The average flow velocity (flow rate/cross-sectional area of the flow channel) is also indicated in Fig. 9. The sensor temperature changed markedly in the flow rate range of 0 to about $1 \mathrm{ml} / \mathrm{min}$ (flow velocity of about $1.5 \mathrm{~cm} / \mathrm{s}$ ). The sensor temperature finally dropped to $36^{\circ} \mathrm{C}$ with increasing flow rate. However, the sensor is sensitive to flow rates in the range of 0 to 8 $\mathrm{ml} / \mathrm{min}$. There was no hysteresis when the flow rate increased and decreased.

In addition to the characterization in water flow, the sensor was also characterized in a flow of a viscous fluid $\left(50 \%\right.$ aqueous solution of glycerol, $\left.36^{\circ} \mathrm{C}\right)$ whose viscosity is similar to that of blood $\left(3.5 \mathrm{cP}\right.$ at $\left.36^{\circ} \mathrm{C}\right)$. The temperature of the sensor was controlled below $42^{\circ} \mathrm{C}$ when the heating current was $10 \mathrm{~mA}$ or less. The maximum temperature of the sensor in the viscous solution was slightly higher than that in water.

Figure 10 shows the output voltage of the sensor as a function of flow rate of the viscous solution $\left(36^{\circ} \mathrm{C}\right)$ for various constant heating currents. The sensor temperatures in standing fluid were 41.2 and $39.1^{\circ} \mathrm{C}$, when the heating currents were 10 and $8 \mathrm{~mA}$, 


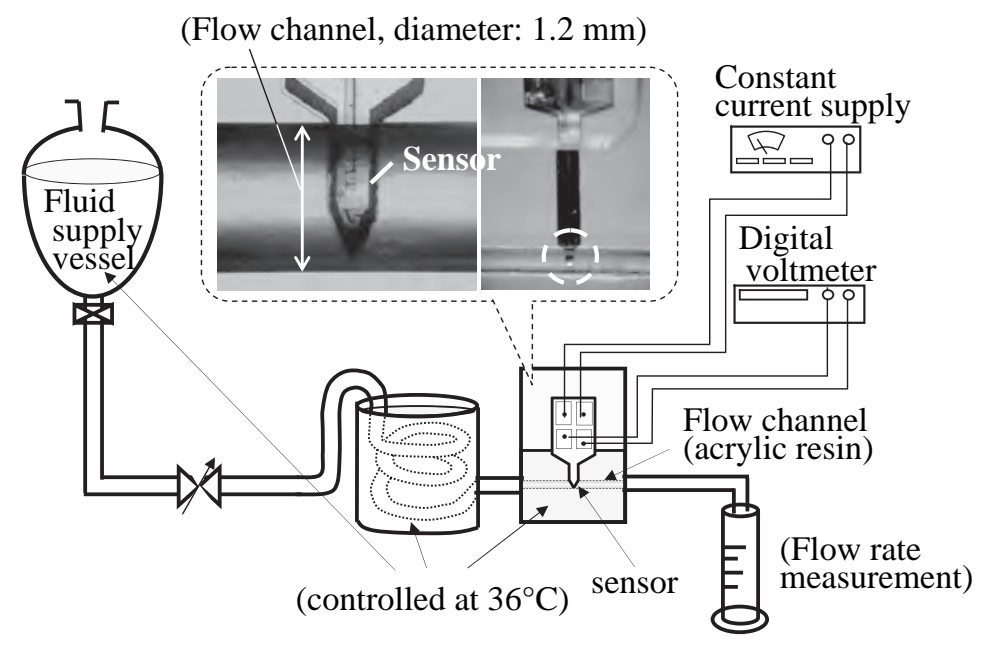

Fig. 7. Setup for flow sensing evaluation.

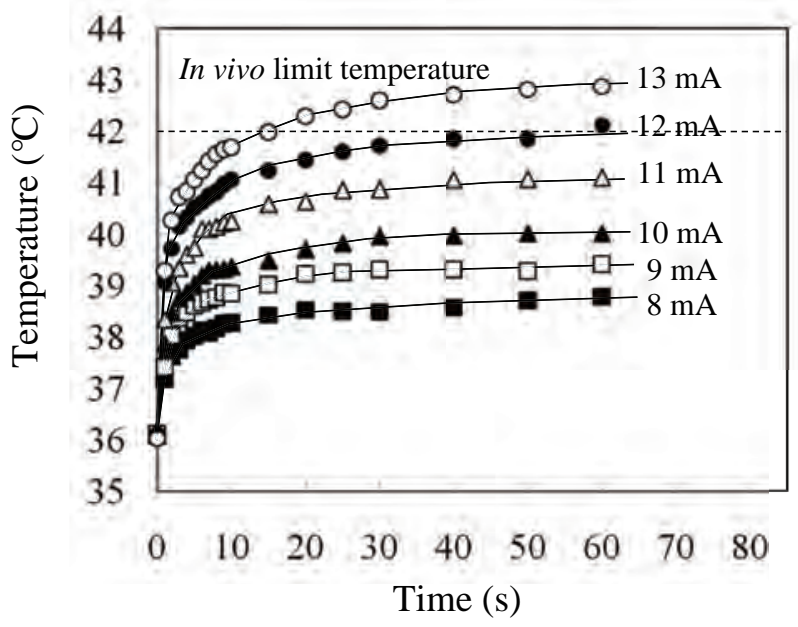

Fig. 8. Sensor temperature change during heating with various heating currents (in standing $36^{\circ} \mathrm{C}$ water).

respectively. Similar to the case of water flow, the sensor temperature fell markedly in the small-flow-rate region, then saturated to the temperature of the fluid $\left(36^{\circ} \mathrm{C}\right)$. With a heating current of $10 \mathrm{~mA}$, the sensor is sensitive in the flow rate range of 0 to $7 \mathrm{ml} /$ min. This result indicates that the sensor can detect a slight decrease in blood flow from the normal value (several $\mathrm{ml} / \mathrm{min}$ in vein), when the blood flow is slightly obstructed in early-stage thrombosis. On the other hand, when the heating current was $8 \mathrm{~mA}$, the sensor temperature fell markedly and was saturated at the smaller flow rate of about 


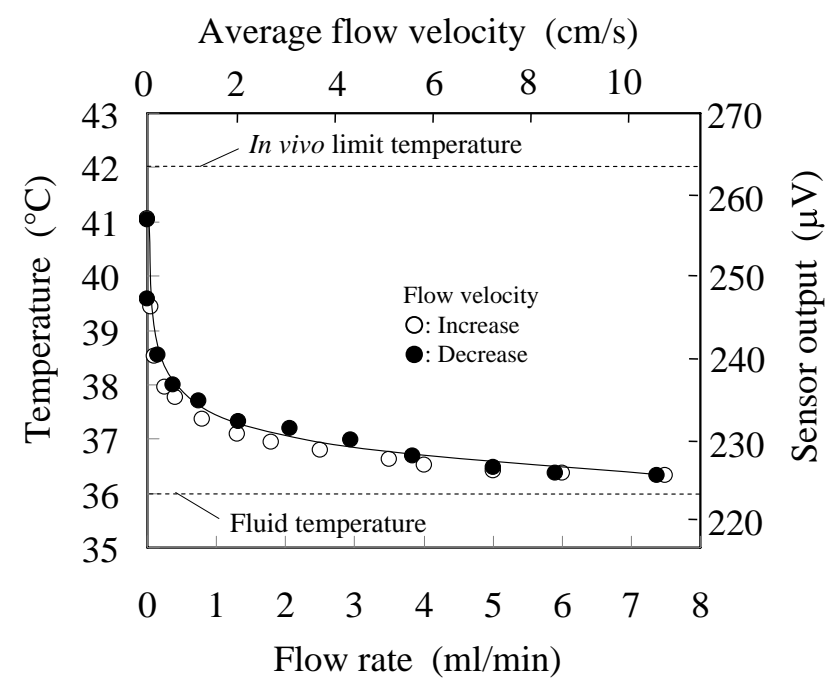

Fig. 9. Output of the sensor as a function of water flow rate (heating current: $11 \mathrm{~mA}$ ).

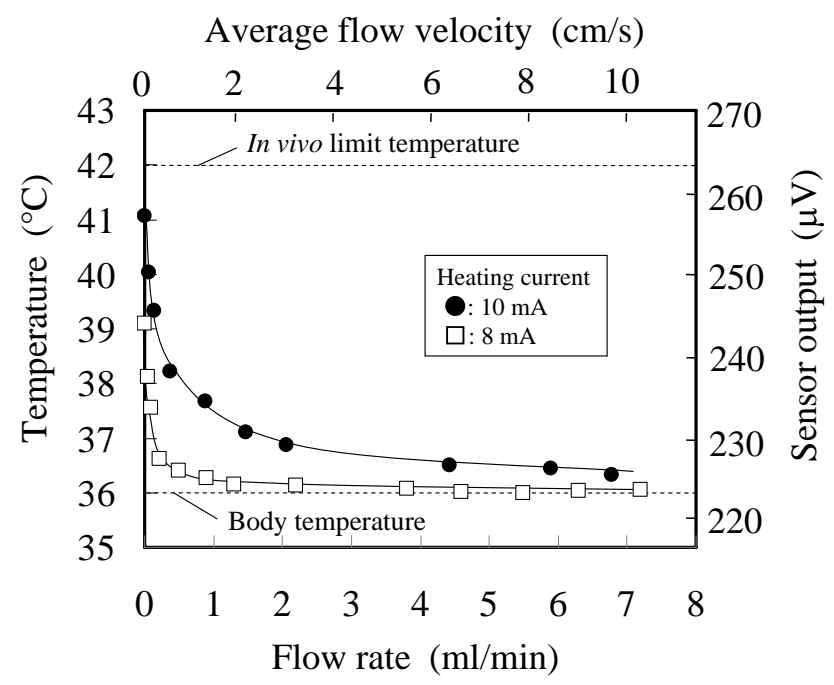

Fig. 10. Sensor output as a function of viscous fluid flow rate with various heating currents.

$1 \mathrm{ml} / \mathrm{min}$. The sensor cannot detect the thrombus formation until the blood flow is significantly obstructed. However, with a heating current of $8 \mathrm{~mA}$, the maximum sensor temperature did not rise to $42^{\circ} \mathrm{C}$ even if it was heated in air. It can safely be used without risk of overheating. 


\section{Conclusion}

In this study, a thermal-type blood flow sensor consisting of a Pt microheater and a Pt-Au microthermocouple on a Ti needle was designed and fabricated. A novel electrochemical etching in LiCl-methanol was successfully used to fabricate the needle from a Ti sheet.

Useful sensing properties of the fabricated sensor were demonstrated in flows of water and a viscous fluid of aqueous $50 \%$ glycerol, whose viscosity is similar to that of blood, in an artificial flow channel with an inner diameter of $1.2 \mathrm{~mm}$. When heated to temperatures below $42^{\circ} \mathrm{C}$, which is the upper limit temperature in vivo, the sensor was sufficiently sensitive to measure a flow velocity of less than $1 \mathrm{~cm} / \mathrm{s}$. This indicates that our sensor has the ability to detect the blood flow decrease due to the obstruction by a thrombus in a vein.

\section{References}

1 H. Machens, P. Mailaender, B. Rieck and A. Berger: Microsurgery 15 (1994) 778.

2 G. M. Kind, R. F. Buntic, G. M. Buncke, T. M. Cooper, P. O. Siko and H. J. J. Buncke: Plast. Reconstr. Surg. 1 (1998) 1268.

3 H. Nornes: Scand. J. Thorac. Cardiovasc. Surg. 10 (1976) 144.

4 T. Sugawara, K. Hirota, M. Watanabe, T. Mineta, E. Makino, S. Toh and T. Shibata: Sens. Actuators, A 130/131 (2006) 461.

5 T. Mineta, N. Kida, S. Satoshi, E. Makino, T. Sugawara, S. Toh and T. Shibata: Sens. Actuators, A 143 (2008) 14.

6 K. Hayashi et al. Eds.: Biomechanical Engineering: A First Course (Maruzen Co., Ltd., Tokyo, 1997) p. 72 (in Japanese).

7 F. Mailly, A. Giani, R. Bonnet, P. Temple-Boyer, F. Pascal-Delannoy, A. Foucaran and A. Boyer: Sens. Actuators, A 94 (2001) 32.

8 T. Yamaguchi, S. Kikkawa, T. Yoshikawa, K. Tanishita and M. Sugawara: J. Biomech. Eng. 105 (1983) 177.

9 Y. Ferri, O. Piotrowski, P.-F. Chauvy, C. Madore and D. Landolt: J. Micromech. Microeng. 11 (2001) 522.

10 T. Mineta: J. Micromech. Microeng. 14 (2004) 76.

11 A. W. Van Herwaarden and P. M. Sarro: Sens. Actuators 10 (1986) 321. 